\title{
System analysis and Design of Tutorial for Teaching Industrial Automatism
}

\author{
Mohamed Najeh Lakhoua ${ }^{1}$, Ala Balti ${ }^{2}$, Imen Mhidhi ${ }^{3}$, Cyrine Noomene ${ }^{3}$ \\ ${ }^{1}$ National Engineering School of Carthage, ENICarthage, University of Carthage, Tunisia. \\ Research Laboratory Smart Electricity \& ICT, SEICT \\ ${ }^{2}$ National Higher Engineering School of Tunis, ENSIT, University of Tunis, Tunisia. \\ ${ }^{3}$ National Engineering School of Carthage, ENICarthage, University of Carthage, Tunisia. \\ Email: MohamedNajeh.Lakhoua@enicarthage.rnu.tn
}

\begin{abstract}
After presenting of the need for using automates in industry, we present an application of system analysis for the design of a tutorial for teaching industrial automatism. The experience is situated in training students in view to get a university degree in engineering. The essential of this methodological approach is to specify the composition of the various teaching modules in industrial automatism to be accessible to the students by a system modeling method and to develop a digital support that can be exploited in distance learning.
\end{abstract}

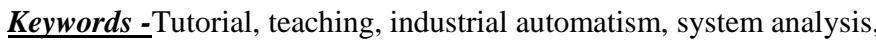
e-learning, specification.

\section{INTRODUCTION}

In industry automates are becoming more and more substantial due to their flexibility, high productivity and high quality [1].

Thanks to the accuracy and speed of nowadays automates impossible tasks are accomplished and hards tasks are no longer a burden for humans being in the industrial sector automation continues to evolve we see a wide variation of automation like industrial instrumentation for measurement and detection, robotics industrial, industrial vision and communication networks automating work activities in the industry is a complex concept because there is lot of techonlogies and yet there will be a lot more to come which will have a remarquable effect on the industry [2], [3].

In fact late researches have proven that emerging technologies take a huge position in the industry wolrd due to its plenty benefits and the new revolution of e-learning this concept has offered a whole new opportunities and new stuning ways of learing for exemple coursewares have overcome many of the traditional limitations and offer a good source of informations in the view of the above, we felt that it was necessary to create a in industrial automation tutorial to ease communication and offer a new way of presenting the information. Indeed, this project is divided into three parts describing the main parts [4].

Generally, a tutorial is classic software teaching assisted by computer to put in a situation, more or less interactive, a student and a problem to answer. This software is specialist and deal with detailed content (robotics, industrial computers, technology...). This software is considered environments specializing in specific topics [5].
The design of this application is based on interactive dialogue, and learning usually involves the center memorizing and training sequences of procedures linked with certain concepts. They are now distributed quite generally in packages to cover an exacting domain connected with a work environment that also includes dedicated tools (word processing, database, etc.) [6].

The tutorial is a practical tool, not only for the authors by sensitizing them to the challenges of learned computer publishing and giving them the tools to develop their mastery of traditional word processing tools, but also for the services and administrative structures that will be gradually more solicited to circulate and promote scientific production by offering models and tools for implementing computer broadcasting projects [7].

The aim of the present study is to demonstrate interests of a tutorial for teaching industrial automatism. The next section briefly presents the concepts of tutorial then e-learning. In Section 3, after presenting a system analysis methodology based for the specification of a tutorial for industrial automatism, this approach is applied to the analysis this project. The last section presents a discussion about impacts of this tutorial on teaching.

\section{PRESENTATION OF TUTORIALS}

Courseware (educational software) refers to a software program especially designed for educational purposes. Initially available on CDs as course help for instructors and helping them manage lectures, courseware has been revolutionized. It is now mostly available online with various resources and supporting material (reference books, research papers and journals) [8].

Today, creating a tutorial is seen as the creative way for a problem resolution. According to William Horton, the realization of a tutorial is based on 4 main stages which are: analysis, design, construction and evaluation.

> analysis : subject and programming language choice

$>$ design : operational objectives definition

$>$ construction : tutorial planification

$>$ evaluation : programming and testing

The step of analysis consists of determining the various objectives targeted through the tutorial. And To have an idea 
about the level of knowledge of the learners before the creation of the Tutorial. Indeed, if the courses established in the Tutorial start at a higher level, some learners will be frustrated very early on and this can discourage them. If, on the other hand, lessons start at a lower level than the learners, some may get bored and stop learning. The ideal would therefore be that the designer takes into account all these variables in order to create a Tutorial so that the learners, at each level, can start at any point or skip those deemed unnecessary. The determination of the initial level of knowledge of the learners can be done by means of questionnaires, tests, interviews, etc [9].

In theis step of seign, the general objectives are transformed into a series of specific objectives, themselves divided into operational objectives these operational objectives are the main activities that a learner must be capable of practising them in his workplace with a certain level of performance,thanks to certain tools the learner can mesure and evaluate his learning outcomes after setting the activities it is neccessary to implement them and while the regrouping phase these activities are well combined with the objectives to create the moduleof the tutoriel in each module we must find components that accomplish the following tasks: present the subject and the goal introduce the title and the contextof the subjects ummarize the main points of a module the last phase is about defining the standards thus the designer must adjust colors,wallpapers ,fonts,interface buttons and other details so that all of this contributes to the success of the learning. The designer will manage to give clear, precise and concise presentations [9].

In the last step of construction consist of creating the learning activities by selecting the appropriate technologies and creating the necessary media. The designer will have to use certain tricks and techniques to reduce the development effort, while ensuring the quality of the work [9].

The evaluation phase allows us to highlight the failures and shortcomings in order to find out whether the Tutorial actually generates good results or not. To measure the effectiveness of a tutorial few samples are choosen and tested before the launch of the tutorial. One more test is required after using the courseware it aims to compare the first test result and the second so the designer can easly tell the failures of the courseware [9].

The main objectives of tutorials are:

- The acquisition of knowledge and skills.

- The procuration of know-how.

- The development of knowledge.

- The acquisition of logic.

Since the goal is to reinforce certain skills in certain fields, the courseware seemed to meet this expectation in an effective way.

In addition, it would allow operators to test themselves in order to stay on top of their skills. Indeed, the courseware offers the possibility to "refresh", and to check if they are still able to respond to the demand [10].

There many types of tutorials:
- Tutorial (Educational): it is a learning tutorial that presents screen pages with text, explanations alternated with questions that the learner must answer before continuing. The way information is presented influences the learning processes (attention) and these processes in turn influence the learning outcome (delivery, performance);

- Exerciser: it is a tutorial consisting essentially of guidelines, statements or questions, expected answers a correction or evaluation mechanism, as well as a feedback mechanism;

- Interactive: it is a tutorial where the activity can be free (educational games, space for exchange between learners, etc.).

\section{PRESENTATION OF E-LEARNING}

The e-learning concept is the result of information and communication technologies (network, videos, conference forums, mails, etc.) and the new training technologies (CRROM, teaching programs, tutorials, etc.) [11].

Learning platfroms are effective tools to diffuse and manage knowledge as well as evaluate the enrolled.

There is no face-to-face learning but learners are followed individually by tutoring in order to eliminate any gap related to distance. The tutoring methods are extremely varied and give birth to technical and educational devices of different natures [12], [13].

In teaching via tutorial, the screen is the main link with the learner. While a page may contain readable text, the screen has less text and more graphics.

Figure 1 below illustrates the simplified operation of memory and sense organs during learning in a digital environment (tutorial).

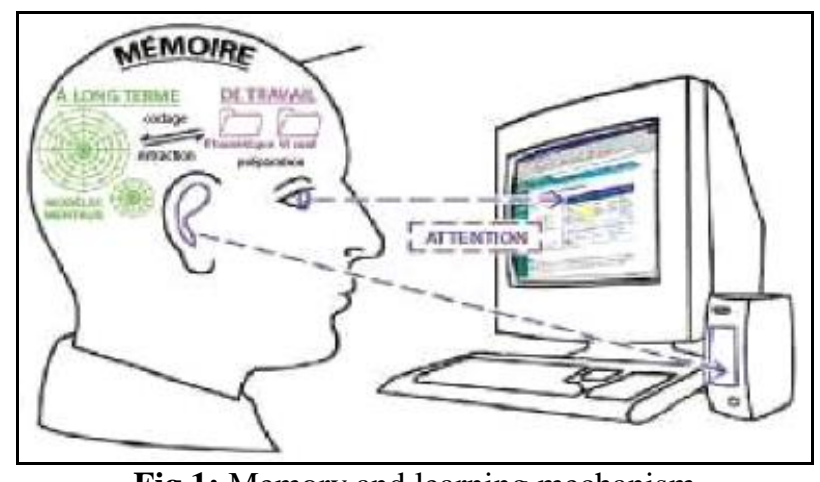

Fig.1: Memory and learning mechanism

Here are the main psychological processes to take into account

- Attention;

- Management of the memory charge;

- Preparing new information in the working memory by coding in long-term memory and transferring new knowledge to the working memory [14].

The learning process involves various interrelated factors. 
Information becomes knowledge through the activities and then the production system of the learner, which is stimulated by motivation and interaction.

The systemic loop allows this new knowledge to feed, in turn, the learning process [15].

IV. SPECIFICATION OF A TUTORIAL

Nowadays, the construction of a tutorial is considered to be a solution to one or many problems. It must follow certain pre-defined and necessary steps which are:

- The choice of the subject and the language programming that is the preliminary point.

- The definition of the operational objectives of the tutorial.

- The planning of the tutorial.

- The programming and testing of the tutorial.

A reflection on these points leads us to adopt a methodology which is to realize a tutorial for teaching robotics on a structured analysis [16], [17]. This is why it is essential to identify the impact of the use of courseware in the teaching automatism [19], [20].

The objective of this planning methodology is to describe the diverse activities of the project [21]. This needs identifying the objectives. It is in this step to organize an integrated and predetermined configuration or to organize and change according to a plan the tutorial [22].

The introduction of assisted learning is the object of any production unit that aims to maximize production and minimize time since the evolution of automated systems, which makes automation one of the most innovative but also most ephemeral sectors [23].

Today the new industrial solutions require new didactic systems. New developments in decentralization and visualization, the introduction of the international standard IEC 131-3 as well as programming industrial controllers according to uniform rules are just few examples of the revolution of professional sectors [24].

In view of the huge demand it is essential today to offer modern learning systems that provide the learner with appropriate knowledge, the main objective remains the survival of companies in a rapidly changing environment.

Focusing on courseware as a learning tool, the elaboration of a courseware can be done in several steps and we choose the OOPP method (Oriented Objective Project Planning) [25], [26] in order to structure our industrial automation courseware.

This analysis allows us to identify four objectives.

- OS1: Presentation and planning of a tutorial for teaching industrial automatism.

- OS2: Composition of a tutorial for teaching industrial automatism.

- OS3: Programming of a tutorial for teaching industrial automatism.

- OS4: Test and maintenance of a tutorial for teaching industrial automatism.

We present on figure 2 the development of the objectives tree of a tutorial for teaching industrial automatism.

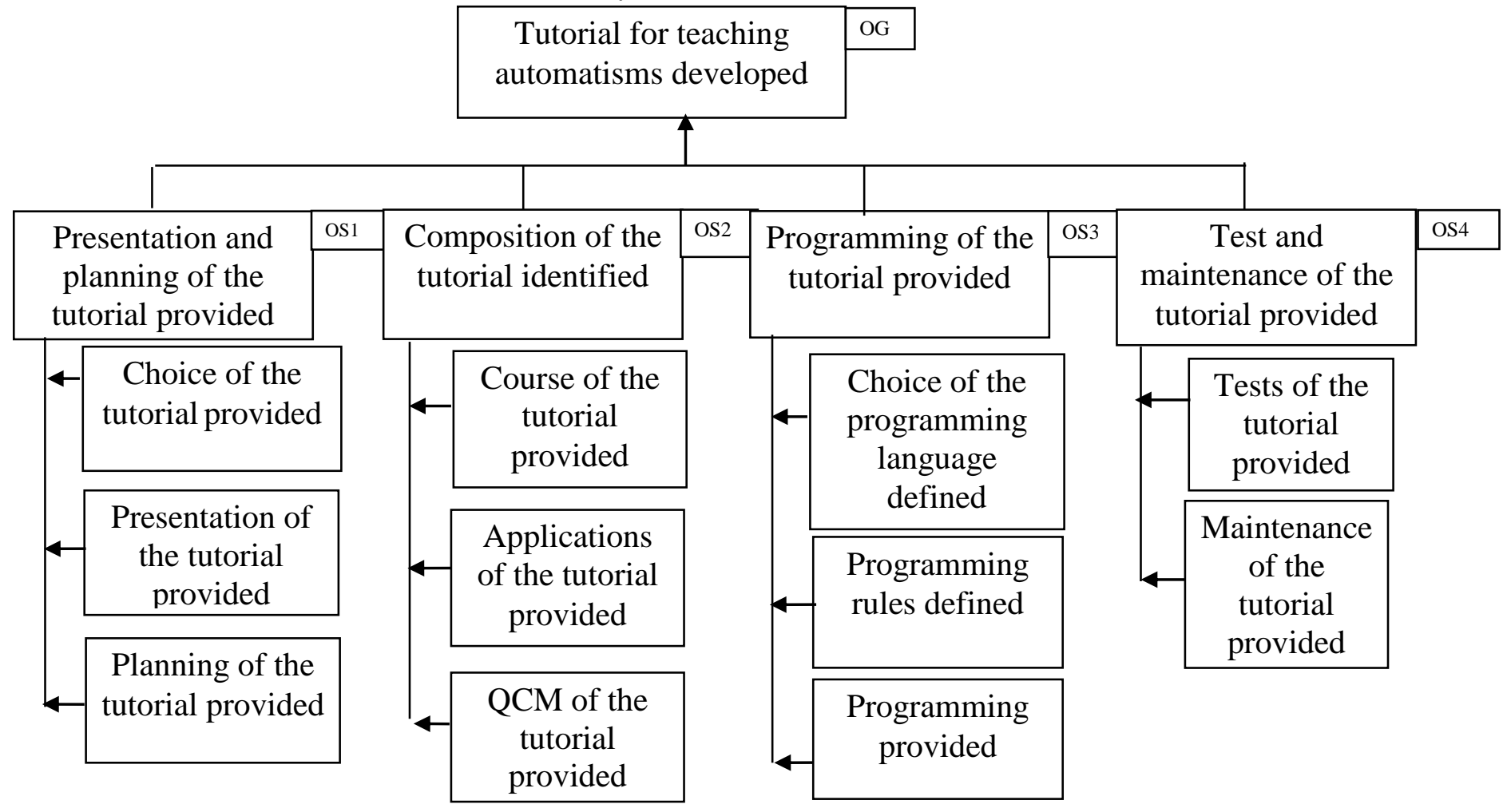

Fig.2- Tree of the objectives of the tutorial for teaching automatisms. 
The tutorial corresponds to methods of transferring information and may be used as a component of a learning process. More interactive and detailed than a book or a lecture tutorial seek to teach by example and provide the information to complete a definite task.

Tutorials usually have the next characteristics:

- A presentation of the view generally explaining and showing the user interface

- A demonstration of a process, using examples to show how a workflow or process is completed; often broken up into discrete modules or sections.

- Some method of review that reinforces or tests understanding of the content in the related module or section.

- A transition to additional modules or sections that builds on the instructions already provided.

This project of designing a tutorial for teaching industrial automatisms also made it possible to form a web platform developed for teaching robotics using HTML platform.

\section{V.CONCLUSION}

By definition, industrial automatism is a multidisciplinary science requiring the collaboration and the participation of several fields of expertise engineering: mechanical engineering; electrical engineering; computer science; physics; mathematics. It simplifies life in several ways and contributes to the technological advancement.

This contribution aims to share teaching experience in higher education for teaching industrial automatism. Methods were applied to improve teaching through active tutorial. The original approach to this tutorial is the specification of the content and that by adopting a system analysis method.

\section{REFERENCES}

[1] R. David et H. Alla, Du Grafcet aux réseaux de Petri, Paris, Hermès, coll. «Traité des nouvelles technologies Automatique », 1992, 2e éd, $500 \mathrm{p}$.

[2] Cottet F., Systèmes temps réel de contrôle - commande, Dunod, Paris 2005.

[3] M. Soberman, Génie Logiciel en informatique de gestion, Eyrolles, Paris 1992.

[4] E.I. Gergely, Laura Coroiu, Helga Maria Silaghi, Dependability Analysis of PLC I/O Systems Used in Critical Industria Applications, Studies in Computational Intelligence 417, 2013, pp. 201-217.

[5] X. Mu, D. Walter, H. Xu, P. Walter, C. Berry, Work in progressvideo-based lab tutorials in an undergraduate Electrical Circuit course, 39th IEEE Frontiers in Education Conference, 2009, pp. $1-2$.

[6] F.H. Cade, Formation à distance, matériel pédagogique et théorie de l'éducation : la cohérence du changement, Journal of Distance Education, 1993.

[7] UNESCO, Forum sur l'impact des didacticiels libres pour l'enseignement supérieur dans les pays en développement, Rapport Final, Paris, 1-3 juillet 2002.

[8] K. Chi Ng, The students' views on the use of the Interwise system in distance education, 7th International Conference on Information Technology Based Higher Education and Training, 2006, pp. 142-146.

[9] R. Absi, M. Lavarde, L. Jeannin, Towards more efficiency in tutorials: Active teaching with modular classroom furniture and movie-making project, IEEE Global Engineering Education Conference (EDUCON), 2018, pp.774-778.

[10] L. Ponzanelli, G. Bavota, A. Mocci, R. Oliveto, M. Penta, S. Cristina Haiduc, B. Russo, M. Lanza, Automatic Identification and Classification of Software Development Video Tutorial Fragments, IEEE Transactions on Software Engineering, 2018.

[11] A. Trekles, S. Nakayama, Work in progress: Identifying adequate level of instruction without hindering deeper learning in distance learning, IEEE Frontiers in Education Conference (FIE), 2010.

[12] J. Guang-bin, S. Shu-yan, Situation and affecting factors of online tutorial in web-based education, International Conference on Electrical and Control Engineering, 2011, pp. 6778-6781.

[13] M. Rotanova, V. Fedorova, V. Kuritsyna, U. Saveleva, Distance learning as a communication strategy for educational environment formation, IEEE Communication Strategies in Digital Society Workshop, 2018.

[14] Z. Ji-chun, G. Jian-xin, Design of distance learning streaming media system based on cloud platform, IEEE 3rd International Conference on Cloud Computing and Big Data Analysis, 2018.

[15] E.A. Koroleva; G. M. David; A. Z. Vladimir; I.I. Makashina ; E. V. Filatova, Advantages of networking and distance learning use in maritime education and training, IEEE Conference of Russian Young Researchers in Electrical and Electronic Engineering, 2018, pp. 61-65.

[16] H.W Wang, J-S Ji, T-P Dong, C-M Chen, J-H Chang, Learning effectiveness of science experiments through cloud multimedia tutorials, 2nd International Conference on Wireless Communication, Vehicular Technology, Information Theory and Aerospace \& Electronic Systems Technology, 2011, pp. 1-6.

[17] The Logical Framework Approach: Handbook for objectivesoriented planning, 1999.

[18] AGCD, Manuel pour l'application de la «Planification des

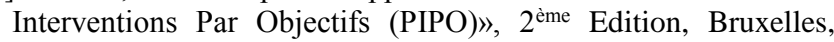
1991.

[19] M.N. Lakhoua, Refining the objectives oriented project planning into method of informational analysis by objectives, International Journal of the Physical Sciences, Vol. 6(33), 2011, pp. 7550 7556 .

[20] G. Kohli, A. Dandriyal, P. Goyal, Enhancing education for IT literacy using spoken tutorials, IEEE International Conference on MOOC, 2014, pp. 366-371.

[21] J. Guang-bin, S. Shu-yan, Situation and affecting factors of online tutorial in web-based education, International Conference on Electrical and Control Engineering, 2011, pp. 6778-6781.

[22] M.N. Lakhoua, F. Khanchel, S. Laifi, S. Khazemi, System analysis of medical equipment for healthcare management, Annals of the Faculty of Engineering Hunedoara 14 (4), 17, 2016.

[23] M.N Lakhoua, J. Ben Salem, L. El Amraoui, The Need for System Analysis based on Two Structured Analysis Methods, Acta Technica Corviniensis, Fascicule 1, 2018.

[24] M.N. Lakhoua, M.F. Karoui, Active Teaching of Project Management Through Tutorials, Sumerianz Journal of Education, Linguistics and Literature, 2020, Vol. 3, No. 1, pp. 1-7 : 26171732 .

[25] M.N. Lakhoua, Systemic analysis of an industrial system: case study of a grain silo, Arabian Journal for Science and Engineering, Springer Publishing, Vol.38, 2013, pp.1243-1254.

[26] M.N. Lakhoua, Systemic Analysis of a Wind Power Station in Tunisia, Journal of Electrical and Electronics Engineering, University of Oradea Publisher, vol.4, $\mathrm{N}^{\circ} 1,2011$

\section{Creative Commons Attribution License 4.0 (Attribution 4.0 International, CC BY 4.0)}

This article is published under the terms of the Creative Commons Attribution License 4.0

https://creativecommons.org/licenses/by/4.0/deed.en_US 